\title{
Tracking the Triple Form of Difference: Deleuze's Bergsonism and the Asymmetrical Synthesis of the Sensible
}

\author{
Craig Lundy \\ Nottingham Trent University \\ Deleuze Studies 11.2 (2017): 174-194 \\ DOI: $10.3366 /$ dls.2017.0261
}

\begin{abstract}
:
This paper will explore the notions of intensity, the virtual/actual and different/ciation in Gilles Deleuze's work. It will focus in particular on excavating the Bergsonian dimension of these terms in Deleuze's philosophy and their relations to one another. While much has been written on the role of Bergson in shaping Deleuze's virtual/actual philosophy, far less attention has been paid to the way in which Deleuze's thoughts on intensity and the movements of different/ciation are also developed out of his reading of Bergson. To address this I will explicate the 'triple form of difference' that Deleuze locates in Bergson, which includes renditions of intensity and the process of differentiation, after which I will map the movements from this early Bergsonian work to Deleuze's mature position on the matter, as it is found in the final chapter of Difference and Repetition.
\end{abstract}

Keywords: intensity, virtual, actual, different/ciation, Bergson, Deleuze

\section{Introduction}

Intensity, the virtual/actual and different/ciation are central concepts for Gilles Deleuze. As has been widely remarked upon within Deleuze studies, Henri Bergson is the primary source for Deleuze's categories of the virtual and actual. Deleuze's debt to Bergson on the notions of intensity and different/ciation, however, has received far less attention. [end of p. 174] The reasons for this are quite straightforward and understandable: in Deleuze's most significant and extensive discussion of intensity and different/ciation - chapter five of Difference and Repetition - Bergson is only mentioned once, and this reference seems at first glance to be a criticism. An objective of this paper will be to demonstrate that contrary to initial appearances Deleuze does not disavow Bergson on the issue of intensity. More broadly, I will seek to show in this paper how Deleuze's mature philosophy of intensity and different/ciation relies heavily on his reading of Bergson, and in this respect could be called Bergsonian. In pursuing this agenda, I will begin by explicating what Deleuze refers to as Bergson's 'triple form of difference'. Following this I will explore its manifestation in Deleuze's later work on intensity, the virtual/actual and different/ciation. Some speculative remarks on connections to the notion of individuation will also be made. From this analysis it is hoped that a greater appreciation will be gained of Deleuze's philosophy of difference, and in particular the genesis of its Bergsonian movements. ${ }^{1}$

\section{The Triple Form of Difference and its Movement as Differentiation}

It is in the final chapter of Difference and Repetition - 'The Asymmetrical Synthesis of the Sensible' - that Deleuze addresses most fully the relation between intensity, the virtual/actual and the processes of different/ciation. The details of this relation, however, are closely prefigured in the final chapter of Deleuze's book on Bergson, Bergsonism. Indeed, chapter five of Bergsonism arguably serves as a blueprint for chapter five of Difference and Repetition. I will attempt to justify this claim later on in this paper, but before doing so let me first explicate the relation of the virtual/actual, intensity and differentiation as it 
appears in Bergsonism. Following this I will elucidate, or perhaps more accurately reinject, the secret Bergsonism of Deleuze's mature position on the subject as it appears in chapter five of Difference and Repetition - 'secret' inasmuch as Deleuze himself fails to adequately acknowledge the connection.

Deleuze published two essays on Bergson in 1956. The first, titled "Bergson, 1859-1941", was an entry for a collection that Maurice Merleau-Ponty was putting together on the history of philosophy, and the second essay was a much longer piece titled "Bergson's Conception of Difference". This second essay was actually first presented by Deleuze in 1954 to the Association of Friends of Bergson, so in a way it is his first essay on Bergson. It [end of p. 175] is also, one could note, the second major piece of scholarship that Deleuze wrote, following closely on the heels of his book Empiricism and Subjectivity (1953) and a full eight years before the publication of his next book Nietasche and Philosophy (1962). ${ }^{2}$ Another way of looking at the two early essays on Bergson, especially if one reads them consecutively in their publication order, is that the first essay is an overview of Bergson's philosophy as a whole, focusing in particular on the method by which Bergsonism proceeds (intuition), while the second essay devotes itself to explaining the novelty and significance of major Bergsonian concepts, most notably his conception and theory of difference. In this way, the two taken together form a miniature version of Deleuze's later book on Bergson, Bergsonism (1966), which will flesh out in greater detail the insights of his two early essays, commencing with a discussion of method before explicating Bergson's principle conceptual contributions. What this tells us, amongst other things, is that although Deleuze's book on Bergson does not come out until 1966, by which time Deleuze has published books on Nietzsche, Kant and Proust, it would be erroneously to think that Deleuze only started working on Bergson after these projects. On the contrary, one could argue, as Eric Alliez does, that Deleuze's work of the early 60s can if not should be read in the light of his already existing Bergsonism. ${ }^{3}$

If we compare the conclusions of the two early essays and Deleuze's book on Bergson, we will find some important similarities - namely, Bergsonism is essentially a philosophy of difference, and what it articulates, to be precise, is a 'triple form of difference' (Deleuze 2004a: 31). These three forms, as they are described in the first essay on Bergson, are: (1) the notion of 'difference of nature'; (2) the coexistent degrees of difference; and (3) the process of differentiation. In Bergsonism, these three are recast as: (1) virtual multiplicity; (2) virtual coexistence; and (3) the actualisation of the virtual according to lines of differentiation (Deleuze 1998: 112-13). These three aspects of difference have been drawn by Deleuze from what he refers to as the three stages or efforts of Bergsonism - duration, memory and the élan vital - the three of which form a whole that progressively emerges as Bergson writes his first three books, Time and Free Will ([1889] 2001), Matter and Memory ([1896] 1994), and Creative Evolution ([1907] 1998). It is in explicating the third stage or form of difference that Deleuze commences his investigation of the relation between the virtual/actual, intensity and differentiation.

Interestingly, Deleuze begins the last chapter of Bergsonism, which is called 'Élan Vital as Movement of Differentiation', with a discussion of intensity. This is interesting because the notion of intensity is only [end of p. 176] very briefly mentioned in Deleuze's early essays on Bergson, and when spoken of it is not exactly given a glowing endorsement. As Deleuze tells us in the early essays, the idea of intensity in Bergson invariably covers over differences of nature with differences in degree and fails to get at the internal difference of a thing in itself, being content to instead distinguish between beings. So when Bergson criticises the reduction of differences in kind to differences in degree in his first book, Time and Free $W i l l$, he is also criticising the reduction of quality to intensity as differences in degree (see Deleuze 2004a: 26; 2004b: 37). My stipulation here to Bergson's first book is of crucial importance, because as Deleuze will point out in Bergsonism, this critique of intensity is by no means Bergson's last word on the matter. In Deleuze's words, Bergson's critique of intensity is "highly ambiguous" (Deleuze 1988: 91). This critique revolves around the idea that intensity is never given in pure experience, but as Deleuze cunningly picks up, if this is the case it might be because intensity is the very thing that produces experience - the quality and extensity of experience. As he says in the opening to chapter five of Bergsonism: "If it is true that intensity is never given in a pure experience, is it not then intensity that gives 
all the qualities with which we make experience?" (92). Intensities, as such, are "included in duration" (92).

In order to explain this 'ambiguity' of intensity, Deleuze quickly runs through a step-by-step explanation - an explanation that effectively summarises the major movements of his book thus far. This progressive explanation of intensity, most crucially, also corresponds to Deleuze's explanation of the 'triple form of difference'. Let us then go back and take a more careful look at the three stages of Bergsonism, for we can now see that this triple form of difference will hold the key to unlocking the developed theory of intensity that Deleuze draws from Bergson - a theory, moreover, that will form the launch pad for Deleuze's 'Asymmetrical Synthesis of the Sensible'.

As with the three-part explication of Bergsonism as a whole, Deleuze starts by reiterating Bergson's point about the confusion of differences of kind with differences in degree, and along with this, the tendency of people to deal in composites without realising it. Bergson's initial task is therefore to 'articulate the real' by separating out differences of nature - the division or de-composition of a composite that discovers differences in kind between actual tendencies. But as we have seen before, if there is something exceptional about Bergson's analysis here, it is that he makes an effort to not merely distinguish between differences in kind - this kind from that kind - but to form a division between differences in kind on the one hand and differences in degree on the [end of p. 177] other. This effort leads us to a notion of internal difference or 'alteration in relation to itself', which is none other than duration - the nature of duration being to continually change, to differ from what it is, which is why it is defined as internal difference.

So on one side of the division we have differences in kind, and on the other side we have differences in degree. Deleuze then says that "between the two there are all the degrees of difference or, in other words, the whole nature of difference" (Deleuze 1988: 93). This might sound like an odd thing to say, but Deleuze has basically spent the previous four chapters of the book preparing for this moment. In the context of Bergsonism, the question has to do with dualism and monism. Bergson would appear to want it both ways: on the one hand he establishes a dualism between kind and degree, but on the other hand he insists on there being a Totality in which the two are reincorporated. The answer to this riddle has to do with the actual and the virtual. When differences were split up into differences in kind on the one hand and differences in degree on the other, what was being divided were 'actual tendencies'. All of these actual tendencies are unified, however, at the level of the virtual, or as Deleuze puts it in Bergsonism, they coexist "in a dimension of depth" (92).

This virtual dimension of depth is best represented by Bergson's infamous cone of memory. To explain the cone in brief, imagine a plane or a circle which contains all of your past; this circle is like a lasso that encircles every single individual memory or moment of your past, where no two are alike, which is to say that each one is singular. Now, this past, by definition, is not 'present', but it is still very much 'real' it does exist, just not as the present. We could therefore say that it is 'virtual', not 'actual', since the actual is defined by Bergson as that which is 'acting' or 'currently in use'. Now imagine another circle, which also contains the whole of your past, but in this instance each moment or memory isn't quite as specific - so for example, all the occasions in which you kissed someone are in a sense grouped together. In this instance, the circle will contain the whole of your past, just like the other one, but the circle will be smaller, more contracted, as it is populated by fewer images. If you were to take all of the possible levels of contraction/expansion and stack them together in descending or ascending order, this stack would resemble a cone. In one respect, we could say that there is a difference in kind between each plane or circle, because each plane is a qualitative multiplicity that cannot be divided without changing in nature - indeed, what distinguishes one circle from another is the way in which a complexe exists; or put differently, the unique memory of [end of p. 178] your first kiss does not merely differ in degree from your memory of all kisses, they differ in kind. But in another respect, we could also say that what distinguishes each level of the cone is the degree of contraction or expansion - the degree of aperture - and in this respect, it is the degree of difference that defines each level. The cone, as a virtual 
whole, is thus at one and the same time 'all the degrees of difference' and the 'whole nature of difference'. In Deleuze's words: “There is no longer any dualism between nature and degrees. All the degrees coexist in a single Nature that is expressed, on the one hand, in differences in kind, and on the other, in differences in degree" (Deleuze 1988: 93). And as Deleuze concludes a few sentences later, bringing the conversation back to intensity: "This is why Bergson is not contradicting himself when he speaks of different intensities or degrees in a virtual coexistence, in a single Time, in a simple Totality" (94). There is no contradiction, because there is a world of difference between intensity as a difference of degree in the actual and intensity as a degree of difference in the virtual.

As will have been noticed, in this discussion of intensity from Bergsonism I have only gone through the first two efforts or stages of difference. The recapitulation that comprises the opening section of chapter five of Bergsonism therefore finishes by bringing us up to the third stage or effort - that being the 'movement of differentiation' - which we can already tell from the chapter title is Bergson's élan vital. Another way of putting this is to say that our journey thus far has gone from actual tendencies in nature to a virtual unity, and what remains for us to explore now is how the virtual comes to be actualised. At this point one might ask: what is the élan vital and what is its relevance here? Deleuze is actually quite clear on this. He says that when Bergson speaks of the élan vital, or 'vital impetus', "it is always a case of a virtuality in the process of being actualized, a simplicity in the process of differentiating, a totality in the process of dividing up" (Deleuze 1988: 94). Differentiation is an actualisation because it presupposes a virtual unity that is then dissociated according to lines of difference. When this happens, it is not as if the actual replaces the virtual, for the virtual totality is carried along in each actualisation. For example, life is split into animal and plant, both of which carry the whole of life, each in their own way. Thus: "Differentiation is always the actualization of a virtuality that persists across its actual divergent lines" (95). Now, most importantly, the division that is being described here is not the same division that we started with. The division that we started with was the division of a composite into differences of nature. This latter division, in contrast, is of the virtual totality, containing all the degrees [end of p. 179] of difference, into "divergent lines differing in kind" (95). So in the first case we are going from mixture to pure kinds, and in the latter case we go from the simple and pure totality of the virtual into diverging lines of actualisation, all of which carry the whole along with it. And unlike the first division, this second division is genetic or generative.

It is at this moment of Bergsonism that Deleuze choses to describe the distinction between the possible and the virtual - a fundamental distinction in Deleuzian ontology that has received no shortage of attention in the secondary literature. Somewhat curiously, this presentation of the distinction appears quite late in the book; given its centrality to Deleuze's Bergsonism going forward, one might have expected to see it feature earlier and more frequently. The reason for its late appearance, however, is because the distinction of the real and the possible with the actual and the virtual does not merely concern ontological categories. More specifically, and importantly, it concerns genetic processes, and asymmetrical ones at that. The explanation of this distinction, as it appears in chapter five of Bergsonism (and is subsequently transplanted to chapter four of Difference and Repetition; see Deleuze 1994: 211-12), roughly goes as follows:

- The possible, as it is commonly understood, is the opposite of the real - it has no reality, it is lacking in reality. The virtual is not the opposite of the real, it is the opposite of the actual (or perhaps more accurately, the complementary dimension to the actual). The virtual and the actual are therefore both real, they possess reality, but different forms of it, one virtual and the other actual.

- The possible is also that which is 'realised', or more exactly, can be realised or not. In other words, according to our conventional understanding of possibility, a possibility is something that is not real but will either be realised or fail to be realised - one or the other. This relation between the possible and the real is subject to two essential rules or principles: "one of resemblance and another of limitation" (Deleuze 1988: 97). 
i. According to the rule of resemblance, the real and the possible are said to resemble one another. As the conventional understanding of possibility would have us think, there are innumerable possibilities laid out before us, one of which is then 'selected' in a process of realisation. In this respect, the possible preexists the real, and the two resemble one another - they look exactly the same, the only difference being that the possible is an 'empty' or 'hollow' [end of p. 180] version while the real is a filled in version of the same image. Put differently, the real is the image of a possible with existence added to it. As such, from the point of view of the concept there is no difference between the possible and the real, for the image of a possibility will look exactly the same as the real that takes on that image when realising it.

ii. This movement from the possible to the real is in turn guided by a rule of limitation or elimination, "by which some possibles are supposed to be repulsed or thwarted, while others 'pass' into the real" (Deleuze 1988: 97).

- In contrast to this, the virtual does not need to be realised, since it is already real. Instead, the virtual becomes actualised. The virtual cannot proceed by eliminating the possibilities before it, for the virtual and the actual do not 'resemble' one another as was the case with the possible and the real - the actual that is actualised is not simply the same shape as the virtual it was, with actuality added to it. The process of actualisation is rather one of differentiation, whereby a virtual unity diverges along different lines. Difference, as opposed to the resemblance of identities, is thus primary in the process of actualisation: what is actualised are lines of divergence, lines of difference that differ according to the way in which differentiation occurs on each of them (similar the different levels of the cone described above). Furthermore, it is in this very act of diverging or splitting that the lines of differentiation are created in the first place. Lines of actualisation therefore do not preexist their reality, such as we find in the conventional schema of the possible and the real, but are created in and through the act of actualisation itself. We can then say that unlike the process of realisation, which obeys the principles of resemblance/identity and limitation/negation, the process of actualisation adheres to the principles of divergence/difference and proliferation/creation. As Deleuze concludes: "the characteristic of virtuality is to exist in such a way that it is actualized by being differentiated and is forced to differentiate itself, to create its lines of differentiation in order to be actualized" (Deleuze 1988: 97).

In order to illustrate what Bergson means by this distinction between the possible/real and the virtual/actual, Deleuze draws on examples of biology (a move he will replicate, looking ahead, in Difference and Repetition). "Evolution", Deleuze says, "takes place from the virtual to actuals. Evolution is actualization, actualization is creation" (Deleuze [end of p. 181] 1988: 98). According to Deleuze, the significance of Bergson's theory of evolution (or part of its significance) is that it rejects both preformism and evolutionism, as those two are conventionally understood. Pre-formism relies upon the conceptual set up of the possible and the real, whereby forms preexist their reality as possibilities. As for evolutionism, it aims to interpret change as the movement from one actual to another actual, rendering a line of divergence in evolutionism as a line-up of actuals. Bergson's creative evolution, by contrast, involves lines of differentiation from the virtual to the actual. Unlike evolutionism, which attempts to move between actuals through a process of addition and association, Bergson's creative evolution moves by way of division and dissociation "from a virtual term to the heterogeneous terms that actualize it along a ramified series" (100).

Halfway through chapter five of Bergsonism Deleuze gives us a handy diagram of differentiation to help explain the situation. The diagram, moving from left to right, begins with a single term or virtual totality, memory-duration, which then divides into matter and life. Life in turn divides into plant and animal, each of which engage in further divisions across the page. The key feature of this diagram is not really the terms 'animal', 'plant', etc. Rather, differentiation is represented in the diagram by the arrows and lines between the terms. When thinking of evolution, it is common to focus on the actuals and compare the terms 'down the page' - plant with animal, instinct with intelligence, etc. But in doing so, 
one is led to locate difference between terms in the same column, and these differences are reflected as one of degree. The paired actuals are also commonly presumed to be the contrary or negative of one another - a negation that is indeed sometimes construed as being that which produces the nature of each to begin with. This manner of thinking, however, misplaces production. According to Bergsonian differentiation, actuals are neither produced nor determined by negating one another. They are instead the result of a diverging line of differentiation that spreads out from the virtual totality to the actual. And this is why differentiation, on Bergson and Deleuze's schema, does not concern the opposition or negation of actuals, but a positive creation that is actualisation. "Each line of actualization", Deleuze will say, "corresponds to a virtual level; but each time, it must invent the figure of this correspondence and create the means for the development of that which was only enveloped [...]" (Deleuze 1988: 106).

Now, to remind, the lines of actualisation do not 'reproduce' or 'resemble' the virtual level of the cone. In the act of differentiation, what coexisted in virtuality ceases to coexist in actuality. Rather, [end of p. 182] the virtual whole is distributed in lines of divergence, each of which retain the whole from a certain perspective or point of view. And it is these lines that are truly creative, not the virtual whole on its own or the actuals on their own. But in saying all this, it must be nevertheless admitted that creation no less involves a closing off. While such a statement immediately calls to mind Nietzsche's Untimely a very important concept for Deleuze (see Lundy 2009) - it is equally assignable to Bergson. The virtual whole, we must remember, is never 'given' as such. The virtual, moreover, doesn't 'do' anything. Rather, as Deleuze puts it in Bergsonism, it is 'acted out', which is to say that it is actualised through a process of differentiation. So in the biological case, "by actualizing itself, by differentiating itself, it loses 'contact with the rest of itself. Every species is thus an arrest of movement; it could be said that the living being turns on itself and closes itself' (Deleuze 1988: 104). This closing off or turning in on itself should not be seen as a bad thing, because without it all would be given and creation would become impossible, a fait accompli. Again, Nietzsche's Untimely works in the same way, but as Deleuze puts it in Bergsonism, we should be "delighted that the Whole is not given", for "There is an efficacy, a positivity of time, that is identical to a 'hesitation' of things and, in this way, to creation in the world" (105).

\section{From the Form and Movement of Difference to the Asymmetrical Synthesis of the Sensible}

The question may now be posed: what relevance is this discussion of the form and movement of difference drawn from Deleuze's early work on Bergson to his mature philosophy of intensity, the virtual/actual and different/ciation as it is found in Difference and Repetition? Given that Bergson is only mentioned once in the 'Asymmetrical Synthesis of Sensible', one might surmise that his influence is minimal at best. A closer comparison of this chapter alongside chapter five of Bergsonism, however, reveals otherwise. For the remainder of this paper I will explore the manner in which Deleuze's underlying Bergsonism manifests in and significantly influences the culminating chapter of Difference and Repetition. Along the way I will also aim to debunk the suggestion that Bergson, according to Deleuze, got intensity wrong.

The first thing to note is that both chapter five of Bergsonism and chapter five of Difference and Repetition share the same trajectory. Both begin with a discussion of intensity before moving to a discussion of differentiation and the relations that intensity forms with the virtual and [end of p. 183] the actual. In both cases this discussion engages quite heavily with the field of evolutionary biology, before finishing with a discussion of the human species and social/ethical relations. ${ }^{5}$ Both chapters also come off the back of a sustained discussion of virtual difference and virtual coexistence - by which I mean more specifically, the problematic nature of a virtual multiplicity. We can then say that both chapters share in not only the direction of their movement and their concern for asymmetrical synthesis, but also their position and function within the book as a whole. 
General affinities aside, let us look more carefully at three major facets of the 'Asymmetrical Synthesis of the Sensible': intensity, different/ciation and individuation. The first task that Deleuze gives himself in chapter five of Difference and Repetition is setting out his notion of intensity or intensive quantities, and he begins this by saying that whereas diversity is 'given', "difference is that by which the given is given" (Deleuze 1994: 222). We are then told that by 'difference' Deleuze specifically means 'intensity': "Intensity is the form of difference in so far as this is the reason of the sensible" (222). Note the similarity here with the opening of chapter five of Bergsonism, discussed above, where Deleuze says: "If it is true that intensity is never given in a pure experience, is it not then intensity that gives all the qualities with which we make experience?" (Deleuze 1988: 92). ${ }^{6}$ The most significant conceptual connection, however, is the obvious affinity between intensity and the Bergsonian notion of internal difference, as it is developed by Deleuze in the two early essays on Bergson. Unlike extensity, which measures the relational difference between external identities and therefore reduces difference to homogeneous identities, intensity concerns an internal dimension - or in order words, depth - which is not an extension but rather the 'heterogeneous dimension' from which extensity emerges. The association that Deleuze draws in this passage between intensive depth and the second synthesis of time from chapter two of Difference and Repetition (otherwise known as the Bergsonian synthesis) confirms the conceptual debt.

The invisible hand of Bergson similarly guides Deleuze in his stipulation of the three characteristics of intensity. To begin with, the notion of internal difference developed by Deleuze in his essay "Bergson's Conception of Difference" provides the primary source for the first characteristic of intensity, the inclusion of the unequal in itself, since duration is described in the same way. The second characteristic of intensity, that it affirms difference, also gets its first run out in the early essays on Bergson. Affirmation is of course a major motif of Deleuze's [end of p. 184] reading of Nietzsche, but this might be one of those instances that Alliez mentioned of Deleuze reading Nietzsche through Bergson (and we can probably say the same thing about depth). At any rate, it is hard to find any major takeaway points from this description of the second characteristic that are not present in the essay on "Bergson's Conception of Difference", such as the assertion that difference is not negation, the latter of which proceeds by limitation and opposition. ${ }^{7}$ As for the third characteristic of intensity, that intensity is implicated and implicating, its Bergsonian tenor is indisputable, for it is here that Deleuze describes intensity as a heterogeneous multiplicity that cannot be divided without changing in nature. ${ }^{8}$ Deleuze even comes to the conclusion that "We must henceforth distinguish between two types of multiplicities" - perhaps his most classic and oft-repeated Bergsonian maneuver (Deleuze 1994: 238).

Such train spotting might seem rather pedantic, but it is worthy of attention when one considers that Bergson is referenced not once by Deleuze in this explication of intensity. In fact, to make matters worse, it is on the very next page following his description of the three characteristics that Deleuze finally mentions Bergson by stating: "This is why the Bergsonian critique of intensity seems unconvincing" (Deleuze 1994: 239). This sentence is followed by a long paragraph, the first half of which explains Bergson's supposed error. As Deleuze recounts, Bergson divides difference into differences in kind and differences in degree. Differences in kind have to do with quality whereas differences in degree have to do with extensity. Deleuze then says that in this set up Bergson has already attributed to the side of quality the various things that Deleuze has been previously describing are the nature of intensity. For instance, Deleuze says: "It is striking that Bergson should define qualitative duration not as indivisible but as that which changes its nature in dividing, that which does not cease to divide and change its nature" (239). But starting from the very next sentence, Deleuze reveals, as he did in chapter five of Bergsonism, that this is not Bergson's last word on the matter:

There comes a moment, however, in this philosophy of Difference which the whole of Bergsonism represents, when Bergson raises the question of the double genesis of quality and extensity. This fundamental differenciation (quality-extensity) can find its reason only in the great synthesis of Memory which allows all the degrees of difference to coexist as degrees of relaxation and contraction, and rediscovers at the heart of duration the implicated order of that intensity which had been denounced only provisionally and from without. (Deleuze 1994: 239) [end of p. 185] 
This 'moment' is exactly what the final chapter of Bergsonism focuses on. At this point in the paragraph Deleuze inserts a long footnote, in which he repeats his discussion of the 'ambiguity' of intensity - that is, the progressive stages of Bergson's triple form of difference. As Deleuze concludes in this highly condensed summary: "hence the reintroduction of intensities within duration, and the idea of a coexistence in duration of all the degrees of relaxation and contraction" (Deleuze 1994: 331, n.14). Or as he otherwise puts it, "beneath the two", that being differences of kind and differences of degree, "lies the entire nature of difference - in other words, the intensive" (239)."

Bergson thus ultimately emerges from this investigation with his reputation intact, and in retrospect we can see the importance of the word 'seems' in the opening salvo of the passage. This recuperation of Bergson was perhaps to be expected, seeing as so many features of Deleuze's notion of intensity, if not the problematic framework itself, can be clearly traced in the first if not foremost instance to his reading of Bergson. ${ }^{10}$

In capping his discussion of intensity, it will be observed that Deleuze engages with Carnot and Curie on the issue of energy and Nietzsche on the manner in which the different returns - the 'eternal return'. While these passages add much richness to Deleuze's notion of intensity, it should be noted that both conversations were initially had in the context of Bergson's philosophy of difference in the mid 1950s. For instance, refer to Deleuze's essay on "Bergson's Conception of Difference" where he says: "Bergson's philosophy comes to completion in a cosmology where everything is changes in tension, changes in energy, and nothing else" (Deleuze 2004b: 47-8). It could be further noted that Deleuze's first engagements with Curie occur through his study of Bergson (Deleuze 2007: 87). As for Nietzsche, it is also no accident that Deleuze's discussion of energy and the 'eternal return' at this point of Difference and Repetition is immediately preceded by his passage on Bergson, which concludes with the statement:

What differences in kind or of degree separate or differenciate, the degrees or nature of difference make the Same, but the same which is said of the different. Bergson, as we have seen, went as far as this extreme conclusion: perhaps this 'same', the identity of nature and degrees of difference, is Repetition (ontological repetition).... (Deleuze 1994: 239-40)

For those familiar with Deleuze's Nietzsche, the connection in this statement between Bergson and the 'eternal return' (arguably with the latter read through the former) is glaring, lending further legitimacy [end of p. 186] to the claim that Deleuze's various developments of intensity through engagements with Carnot/Curie and Nietzsche are grounded in (or at the very least informed by) his longstanding Bergsonism.

Having now articulated a notion of intensity, Deleuze proceeds to put the pieces of his puzzle together - most importantly, the connection between the fourth chapter of Difference and Repetition on Ideas with intensity and the dual process of different/ciation. In his first stab at it, Deleuze says:

Ideas are problematic or 'perplexed' virtual multiplicities, made up of relations between differential elements. Intensities are implicated multiplicities, 'implexes', made up of relations between asymmetrical elements which direct the course of the actualisation of Ideas and determine the cases of solutions for problems. (Deleuze 1994: 244)

Not everything is this quote can be traced back to Deleuze's reading of Bergson, but much of it can, and more of it can than any other single source: the virtual/actual, the theory of multiplicities, the relation of problem and solution, the course of actualisation from a virtual multiplicity to certain 'cases of solutions for problems' - all of this goes back to Bergson. And I say this not just because the ideas initially came from Deleuze's study of Bergson, but also because it is hard to find any major discrepancies between their initial appearance and later presentation in Difference and Repetition enhancements and additions certainly, but that is what they are, enhancements and additions. 
If one thing has changed, it is that Deleuze now spells different/ciation in two different ways, one with $a$ ' $t$ ' and one with a ' $c$ '. While this development is certainly a terminological improvement from his earlier work on the topic, both processes or directions, it should be noted, are very much present in chapter five of Bergsonism. Indeed, they have to be, because this is entirely the point of the analysis: to explain the multifarious connections between the virtual and the actual, including the manner in which a virtual totality of difference is formed and actually dispersed within the process of creation. You will recall that when we were talking about the second stage or form of difference, we ended up with the cone of memory, which was effectively an illustration of difference divided up or differentiated into all its various degrees of difference. But we then went on to describe how these degrees of difference become actualised, and this actualisation was referred to as a 'movement of differentiation'. In both cases, you will have noticed, the word 'differentiation' was used, even though what we were talking about was two quite different things. In the first case, the term refers [end of p. 187] to the movement from actual tendencies to the virtual Whole (or in other words, the second effort of Bergsonism), whereas in the second case, the term refers to the movement from the virtual totality to lines of actualisation (or in other words, the third effort of Bergsonism). In order to better distinguish between the two stages, Deleuze comes up with the very sensible idea of spelling them differently in Difference and Repetition. In this respect, the process that is the main subject of chapter five of Bergsonism is actually differenciation with a ' $c$ '. And to confirm this, on the one occasion that Deleuze mentions Bergson in chapter five of Difference and Repetition, discussed above, the word is spelt with a 'c'.

We now arrive at the question, what is it that connects the differentiation in the virtual with its actualisation in quality and extensity?

Intensity is the determinant in the process of actualisation. It is intensity which dramatises. [...]We speak of differenciation in relation to the Idea which is actualised. We speak of explication in relation to the intensity which 'develops' and which, precisely, determines the movement of actualisation. However, it remains literally true that intensity creates the qualities and extensities in which it explicates itself, because these qualities and extensities do not in any way resemble the ideal relations which are actualised within them: differenciation implies the creation of the lines along which it operates. (Deleuze 1994: 245-6)

Once again, much of this very important passage finds its genesis in Deleuze's early study of Bergson, and not just tangentially, but explicitly. Firstly, intensity is what 'dramatises', or as he put it in Bergsonism, it is the 'acting out' of the virtual Whole. Secondly, as we saw in the discussion of the possible/real and virtual/actual, the lines of differenciation do not preexist their actualisation but are rather created in their explication, and not a moment before or after. Thirdly, we also saw in the same discussion why it is inappropriate to say that the explicated qualities and extensities 'resemble' the virtual relations to which they correspond. And finally, as a fourth point (though perhaps of less significance), to better explain himself in this passage Deleuze uses the example of colour, which was the same example he used in "Bergson's Conception of Difference" to explain Bergson's philosophy of differentiation (Deleuze 2004b: 43), this example itself being taken from Bergson's essay on Félix Ravaisson (Bergson 2007).

So we now know that intensity is what determines actualisation, but what is it that determines intensity? "Individuation is the act by which [end of p. 188] intensity determines differential relations to be actualised, along the lines of differenciation and within the qualities and extensities it creates" (Deleuze 1994: 246). The upshot of this is "that individuation precedes differenciation in principle, that every differenciation presupposes a prior intense field of individuation" (Deleuze 1994: 247). If there has been a great advancement in Deleuze's thinking on this point since his earlier work on Bergson (in the context of chapter five of Difference and Repetition), it is perhaps his engagement with Gilbert Simondon and the development of individuation as a notion. That being said, I would point out that the biological discussion which occurs on this issue is a direct continuation of Deleuze's engagement with Bergson's Creative Evolution, which comprises the bulk of chapter five of Bergsonism and is first discussed by 
Deleuze in his two essays on Bergson from the mid 1950s. ${ }^{11}$ In this respect, I think it would be fair to say that Deleuze was well and truly primed to receive Simondon's work on individuation. Or put differently, Simondon greatly enhances and advances Deleuze's thinking on the problem, but he does not give him the problem.

To further justify this claim let us go back again to Deleuze's second essay on Bergson, first written four years before Simondon defended his thesis. As Deleuze tells us there, Bergson's aim, contra Kant, is not to articulate the conditions of all possible experience, but to reach the conditions of real experience. So the purpose of Bergson's method of intuition is to reach the conditions of the given, which, Deleuze importantly points out, are given in a certain way: "they are lived" (Deleuze 2004b: 36; emphasis added). What is more, as he goes on to say:

$[\ldots]$ they are at once the pure and the lived, the living and the lived, the absolute and the lived. [...] These conditions can and must be grasped in an intuition precisely because they are the conditions of real experience, because they are not broader than what is conditioned, because the concept they form is identical to its object. It will come as no surprise, then, that a kind of principle of sufficient reason, as well as indiscernibles, can be found in Bergson's work. What he rejects is a distribution that locates cause or reason in the genus and the category and abandons the individual to contingency, stranding bim in space. Reason must reach all the way to the individual, the genuine concept all the way to the thing, and comprehension all the way to 'this'. (Deleuze 2004b: 36; emphasis added)

What we see from this passage is that Deleuze's Bergsonism, at bottom, consists in developing and employing a method (intuition) that is capable [end of p. 189] of reaching the conditions of real experience, which is to say the unique paring of a thing and a concept, and to do this the cause or reason of a thing cannot be reduced to or subsumed under categories such as species; instead, reason must be able to reach all the way to the individual (and vice versa we might add), since the conditions are 'lived'. In chapter five of Bergsonism Deleuze spells this out in the context of biology, but let us jump to the corresponding discussion of individuation in Difference and Repetition, where Deleuze now says:

The great taxonomic units - genera, families, orders and classes - no longer provide a means of understanding difference by relating it to such apparent conditions as resemblances, identities, analogies and determined oppositions. On the contrary, these taxonomic units are understood on the basis of such fundamental mechanisms of natural selection as difference and the differenciation of difference. (Deleuze 1994: 248)

And in the next paragraph:

\begin{abstract}
Baer concludes that epigenesis proceeds from more to less general - in other words, from the most general types to generic and specific determinations. However, this high level of generality has nothing to do with an abstract taxonomic concept since it is, as such, lived by the embryo. It refers, on the one hand, to the differential relations which constitute the virtuality which exists prior to the actualisation of the species; on the other hand, it refers to the first movements of that actualisation, and particularly to its condition - namely, individuation as it finds its field of constitution in the egg. (Deleuze 1994: 249)
\end{abstract}

There are several other clear connections that I could draw from this passage of Difference and Repetition to Bergsonism, such as the discussion of 'pre-formism' and 'evolutionism', or the 'principle of indiscernibles', which as we saw just a moment ago is found by Deleuze in the work of Bergson. But I would like to finish by noting that these discussions of categories and eggs are advanced by Deleuze for the reason that they illustrate how individuation emerges like the act of solving a problem. In Deleuze's words: "The act of individuation consists not in suppressing the problem, but in integrating the elements of the disparateness into a state of coupling which ensures its internal resonance" (Deleuze 1994: 246). This is why, as Deleuze puts it in chapter five of Bergsonism, "the living being, in relation to matter, appears primarily as the stating of a problem, and the capacity to solve problems" (Deleuze 1988: 103). The biological example that Deleuze goes on to cite there, well known amongst 
Bergsonians, is the construction of an eye, which is "primarily the solution to a problem posed in terms of [end of p. 190] light" (Deleuze 1988: 103). ${ }^{12}$ Therefore, while the term 'individuation' might not appear much in Deleuze's earlier work on Bergson, perhaps we could say that it is already there, as a 'dark precursor'. Put differently, it is through an engagement with Bergson that the problematic field is first laid out by Deleuze, the full articulation of individuation being one notion that emerges when he comes to explain this problem as the asymmetrical synthesis of the sensible.

\section{Conclusion}

It has not been the aim of this paper to reduce the entirety of Deleuze's thoughts on intensity, the virtual/actual and different/ciation to Bergson. As one of the great philosophical texts of the $20^{\text {th }}$ century, Difference and Repetition, to put it mildly, is a work of breathtaking originality that draws on and synthesises insights from an enormous range of sources. Nevertheless, it is hard to deny that Deleuze's reading of Bergson plays a significant role in shaping his understanding of the relations between intensity, the virtual/actual and different/ciation (not to mention individuation), and that this role has been somewhat obscured in that text, judging by the paucity of references to Bergson in the final chapter. Moreover, the situation has been exacerbated by the one reference to Bergson that does appear in the 'Asymmetrical Synthesis of the Sensible', given that at first glance it appears to be a critique and thus rejection of Bergson. For these reasons, a re-reading of Difference and Repetition's final chapter alongside the corresponding chapter of Bergsonism (and prior affiliated essays) would appear to be a worthy and justified exercise - one, I would also wager, that can usefully contribute to our understanding of the relations between intensity, the virtual/actual and different/ciation in Deleuze's philosophy of difference. ${ }^{13}$

\section{Notes}

${ }^{1}$ It should be noted that it is not an objective of this paper to ascertain the extent to which Deleuze's reading of Bergson departs from Bergson himself. While such a task would be no doubt interesting and important, this paper is rather concerned with excavating how Deleuze's Bergsonism influences his mature philosophy of intensity, the virtual/actual and different/ciation - the significance of which is established below. To this end, the issue of Deleuze's fidelity to Bergson is tangential; and for the same reasons, the appropriate resources for establishing and defending the paper's main claims are Deleuze's early writings on Bergson, not Bergson's texts. [end of p. 191]

2 While certainly important, I have omitted from this assessment the various book reviews and other pieces under ten pages that Deleuze wrote between 1953 and 1955.

${ }^{3}$ Alliez in fact goes farther than this, suggesting that Deleuze's 'late' discovery of Nietzsche was “inspired by his initial studies of Bergson". See Alliez 1998: 227-8. See also Borradori 1999; Gunter 2009. In this paper Gunter further points out that Deleuze published a selection of Bergson's writings under the title Memoire et vie in 1957, with a new edition published in 1963.

${ }^{4}$ Deleuzians will of course be aware that Bergson features in earlier parts of Difference and Repetition, most notably in Deleuze's discussion of the 'three syntheses of time' and ideas as 'virtual multiplicities'. These discussions are most certainly connected to the 'Asymmetrical Synthesis of the Sensible', but this if anything makes the failure of Deleuze to acknowledge the importance of Bergson in chapter five even more perplexing.

5 "Speaking of evolution necessarily leads us to psychic systems" (Deleuze 1994: 256).

${ }^{6}$ Deleuze also notes in this opening that the fact that everything is not given, "forms the condition of the world", where the world is "regarded as a 'remainder" - another point, which I mentioned earlier, that was made in chapter five of Bergsonism.

${ }^{7}$ See above for the relevant discussion of 'limitation' in Deleuze's Bergsonism. As for 'opposition', see the essay on "Bergson's Conception of Difference", and in particular the following passage: "Everything comes back to Bergson's critique of the negative: his whole effort is aimed at a conception of difference without negation, a conception of difference that does not contain the negative. In his critique of disorder, as well as his critique of 
nothingness or contradiction, Bergson tries to show that the negation of one real term by the other is only the positive actualization of a virtuality that contains both terms at once. [...] It is our ignorance of the virtual that makes us believe in contradiction and negation. The opposition of two terms is only the actualization of a virtuality that contained them both: this is tantamount to saying that difference is more profound than negation or contradiction." (Deleuze 2004b: 42-3) We should also not be surprised that the critique of Plato in this section of Difference and Repetition also originally comes from the essay "Bergson's Conception of Difference".

8 As Deleuze puts it in the second essay on Bergson: "duration is that which differs or that which changes nature, quality, heterogeneity, what differs from itself." (Deleuze 2004a: 26)

${ }^{9}$ Deleuze will also use the term 'beneath' in the first essay on Bergson (see Deleuze 2004a: 24).

${ }^{10}$ While it might be argued that Deleuze is only able to 'save' Bergson by 'changing' him, such a stance would not invalidate my major point here: that Deleuze's understanding of intensity is significantly shaped by his engagement with Bergson and the favourable reading of Bergsonian intensity that he develops in the 1950s and early $60 \mathrm{~s}$, even if this reading is ultimately deemed by other scholars to be on the creative side.

${ }^{11}$ See also Deleuze 2007: 89: "So, what is the origin of individuation? It is this resistance of a matter that is opposed to life."

12 At this point of the text Deleuze adds in a footnote: "This character of life, posing and solution of a problem, appears to Bergson to be more important than the negative determination of need" (Deleuze 1988: 133, n.15).

${ }^{13}$ While there has been some excellent scholarship published on Difference and Repetition that naturally discusses Deleuze's reading of Bergson, tracking the connections between the final chapters of Bergsonism and Difference and Repetition vis-à-vis Deleuze's earlier work on Bergson has not featured in this material. I am predominantly thinking here of Williams 2003; Hughes 2009; Somers-Hall 2013; Bryant 2008. Bryant's book discusses the Deleuze-Bergson connection at length, but is silent when it comes to chapter five of Bergsonism (despite his interest on 'givenness' and extensive treatment of actualisation, different/ciation and individuation). Bryant also argues that Deleuze disavows Bergson in favour of Kant on intensity (Bryant 2008: 242-4). The major exception to the above would be Keith Ansell Pearson's outstanding Germinal Life: The Difference and Repetition of Deleure (1999). It could be noted, however, that Ansell Pearson's discussion of the final chapter of Bergsonism does not focus to the same extent as this paper on its ramifications for the corresponding discussions in Difference and Repetition, and when he does touch on this topic Ansell Pearson's aim is to explore how Deleuze's mature philosophy departs from Bergson's original work - a task ancillary to this paper (see footnote 1), thus rendering our treatments complimentary.

\section{References}

Alliez, Eric (1998) 'On Deleuze’s Bergsonism', Discourse, 20:3, pp. 226-46.

Ansell-Pearson, Keith (1999) Germinal Life: The Difference and Repetition of Deleure, New York: Routledge. Bergson, Henri [1896] (1994) Matter and Memory, trans. Nancy Margaret Paul and W. Scott Palmer, New York: Zone Books.

Bergson, Henri [1907] (1998) Creative Evolution, trans. Arthur Mitchell, Mineola, NY: Dover.

Bergson, Henri [1889] (2001) Time and Free Will: An Essay on the Immediate Data of Consciousness, trans. F.

L. Pogson, Mineola, NY: Dover.

Bergson, Henri (2007) 'The Life and Work of Ravaisson', in The Creative Mind: An Introduction to

Metaphysics, trans. Mabelle L. Andison, Mineola, NY: Dover Publications, pp. 187-216.

Borradori, Giovanna (1999) 'On the Presence of Bergson in Deleuze's Nietzsche', Philosophy Today, 43, pp. $140-5$.

Bryant, Levi (2008) Difference and Givenness: Deleuze's Transcendental Empiricism and the Ontology of Immanence, Evanston, IL: Northwestern University Press.

Deleuze, Gilles (1994) Difference and Repetition, trans. Paul Patton, New York: Columbia University Press.

Deleuze, Gilles (1988) Bergsonism, trans. Hugh Tomlinson and Barbara Habberjam, New York: Zone Books. 
Deleuze, Gilles (2004a) 'Bergson, 1859-1941', in Desert Islands and Other Texts: 1953-1974, trans.

Michael Taormina, Los Angeles and New York: Semiotext(e), pp. 22-31.

Deleuze, Gilles (2004b) 'Bergson's Conception of Difference', in Desert Islands and Other Texts: 19531974, trans. Michael Taormina, Los Angeles and New York: Semiotext(e), pp. 32-51.

Deleuze, Gilles (2007) 'Lecture Course on Chapter Three of Bergson's Creative Evolution - 2nd May 1960', SubStance, issue 114, 36:3, pp. 72-90.

Gunter, Peter (2009) 'Gilles Deleuze, Deleuze's Bergson and Bergson Himself', in Keith Robinson (ed.), Deleure, Whitehead, Bergson: Rhizomatic Connections, New York: Palgrave, pp. 167-80.

Hughes, Joe (2009) Deleure's Difference and Repetition: A Reader's Guide, London: Continuum.

[end of p. 193]

Lundy, Craig (2009) 'Deleuze's Untimely: Uses and Abuses in the Appropriation of Nietzsche', in Jeffrey A. Bell and Claire Colebrook (eds), Deleuze and History, Edinburgh: Edinburgh University Press, pp. 188-205.

Somers-Hall, Henry (2013) Deleuze's Difference and Repetition, Edinburgh: Edinburgh University Press. Williams, James (2003) Gilles Deleuze's Difference and Repetition: A Critical Introduction and Guide, Edinburgh: Edinburgh University Press. 